\title{
KARABAĞ SORUNU ÜZERINE BIR NOT
}

\author{
Prof.Dr. Şükrü S. GÜREL
}

Sovyetler Birliği'nin 1991 sonunda dağılıp. Bağımsız Devletler Topluluğu'na dönüşmesi, 1992 yılında Kafkaslar ve Orta asya'daki yeni bağımsız Türk devletleriyle Türkiye arasında yepyeni ilişki ufuklarının açılmasını sağladı. Eski Sovyet cumhuriyetleri çok hızlı fakat kansız bir sürecin sonunda bağımsız devletlere dönüştüler ama, bu devletler arasındaki ilişkilerin uyum ve işbirliği içinde sürdürülmesinin de pek kolay olmayacağı kısa sürcde ortaya çıkt. Kafkasya ve Orta Asya'daki belirsizlik ve istikrarsızlık başlıca şu üç nedene bağlanarak yorumlanabilir :

1. Bağımsız Devletler Topluluğu'nun nasıl bir siyasal çerçeve oluşturacağının belirlenememesi : Sovyctler Birliği, bu birligge üye olan cumhuriyetler arasında Rus unsurun başat olduğu bir düzen sağlamış, siyasal ve iktisadi ilişkiler, eşitsizlik ve üstünlük ilişkilerine dayansa da, belirli bir düzenlilik içinde yürütülebilmişti. Şimdi, Bağımsız Devletler topluluğu, benzeri bir işlevi üstlenmekten uzak olduğu gibi, henüz gevşek bir siyasal çerçeve oluşturmaktan bile uzak görünmektedir.

2. Şimdi, yeni bağımsız devletlerin yepyeni bir siyasal ve ekonomik düzen kurmakıa zorlandıkları ve bunun toplumsal istikrarsızlık yarauı̆̆ı görülmektedir.

3. Sovyetler Birliģi'nin oluş̧urduğu kısıllayıcı çerçeve ortadan kalkınca, yeni devletlerin tarihten süzülüp gelen karşıtlı ve sorunları alevlenip, su yüzüne çıkmışır. Bu sorunlar arasında kuşkusuz en önde gelenleri, toprak anlaşmazlıklarıdır.

Azcrbaycan ile Ermenistan arasinda 1980'lerin sonlarında yeniden alevlenen ve 1992 yılı içinde de Ermenistan devletinin desteğinde bölgedeki Ermeni silahlı grupların giriştił̧i ve soykırım niteliğini alan bir katliamla doruğuna ulaşan' Dał̆lık Karabał̆ sorunu, yukarıda ana çizgileri belirtilmeğe çalışılan yeni siyasal gerçeklerin ortaya çıkartığı en önemli sorunlardan biridir. Bu kısa not ile, Dağlık Karabağ sorununa genel bir tanım ve çerçeve getirilmeğe çalışılmaktadır. 


\section{TARIH 1}

Bugün Azerbaycan diyc anılan bőlgenin bütünü, uzun bir süre Pcrs egcmenliģi alunda kalmışır. Yedinci Yüzyıldan, yani bölgede Arap egemenliği başladıktan sonra, bölgede yaşayanların Zerdüşı dininden aynlarak, Islamı benimsedikleri bilinir. Onbirinci Yüzyılda ise, bőlgeye gelen Oğuz Türkleri, bölgenin dilini Türkçcleş̧irmiş ve burada Islamiyeti kabul etmiştir. Türklerin (Selçukluların) bölgedeki egemenlił̧ine son veren Mogol istilası olmuştur. Onüçünıü Yüzyıl, Moğol istilasının yaşandığı ve ardından gelen llhanlı egemenliłinin başladığı dönemdir. tlhanlıların ardından ise, Türkmenlerin devletleri olan Karakoyunlu ve Akkoyunlu devleıleri bölgeye egemen olmuşlardır.

Onbeşinci Yüzyılda bölgescl bir devlet olan Şirvan Şahların Azcri devleti ortaya çıkmışıtır. Onaltıncı Yüzyı! ba:̧larında ise Azerbaycan, Safevi soyunun kurduğu imparatorlugun merkęz güç bölgesi durumuna geleccktir. Safevi soyunun bölgedcki egemenliği iki yüz yıldan fazla sürecck ve bu devlet, 1722'de iç kargaşa ve Afgan istilası sonunda yıkılacakur.

Onsekizinci Yüzyıl ortalarıłłan başlayarak, bölgede (bugünkü Azerbaycan ile Iran Azerbaycanı'nda) dokuz hanlık kurulmuştur. Bunlardan biri olan Karabağ Hanlığı. Ondokuzuncu Yüzyıl başlarına kadar bağımsızlığını sürdürecektir.

Ruslar, Onsekizinci Yïzyıl sonlarından başlayarak Kuzey Karadeniz ve Kafkasya'da yayılmağa başlămışlardır. Önce, Karabą̆ da dahil bazı hanlıkları, 1800'lerin başlarında 'himaye antlaşmaları'yla kendisine bağlayan Rusya, ardından da óteki Azcri hanlıklarını silah zoruyla ele geçirmeğe çalışmışur.

Rusya, Azerbaycan'ı ülkcsine katmağa çalışırken, Azcri hanlıklarının dışında, başlıca iki büyük engeli altetmek zorunda kalacaktı. Bunlardan birincisi, Iran olmuştur. Ikincisi ise, Azerbaycan'ı hị̧bir zaman denetimi aluna almamı̧ olmasına karşın, bölgenin otteki ónemli gücü olan Osmanlı Devleti'dir. Rusya, önce Iran'ı yenilgiye uğratıp, bu devletle 1828 Türkmençay Anılaşması'nı yapmış, ardından da 1828 - 1829 Savaşında yendiği Osmanlı Devleti ile Edime Barışı'nı imzalamışırı. Rusya'nın, Iran Azerbaycanı dışında kalan Azerbaycan'a -yani bugünkü Azerbaycan'a- egemen olması böylece gerçekleşmiştir.

Daha once Karabağ'da çok az sayıda bulunan Ermenilerin bu bölgedeki varlığ, 1828'den sonra izlenen Rus politikasıyla hızla artmışur. Zaten, Ermeniler de 1978'de Karabag'daki varlıklarının 150'nci yıldönümünü kutlamışlardır. Dağlık Karabał'da, 1919 yılında , Ingiliz verilerine göre, Azeri - Ermeni nüfus oranı üçe iki Azcrilerin lehincydi. ${ }^{2}$ Ermeni nüfusun Dağlık Karabığda bugünkü gibi çoğunluk durumuna gelmesi, Sovyculer Birligi yönetimi alunda olmuş̧ur.

Birinci Dünya Savaşı sonunda bölgcyi önce Osmanlılar, ardından da Ingiliziłcr işgal etmişler ve 28 Mayıs 1918'de kuruluşu ilan edilmiş bulunan Azcrbaycan, Devleti de

\footnotetext{
${ }^{1}$ Azerbaycan tarihi için özellikle bkz. : Tadcusz Swictochowski, Russian Azcrbaijan, 1905. 1920. The Shaping of National Identity in a Muslim Community, Cambridge. Cambridge University Press, 1985.

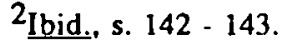


Ingiliz üstünlügü altına girmiştir. Bunun ardından, 1920 Nisan'ı sonunda Sovyetler Birliģi bölgede egemen olmuş ve Azcrbaycan da bu devletin içinde bir Cumhuriyet olarak yer almışur.

Türkiye Büyük Millet Meclisi Hükümcti, Kafkaslardaki komşulanyla bir dizi antlaşma imzalayarak bu bölgedeki sınırları belirlemiştir. TBMM Hükümeti ile Ermenistan arasinda 2 Aralık 1920 tarihinde imzalanan Gümrü Barış Antlaşması yürürlüğge girmemiştir. Moskova'da 16 Mart 1921'de imzalanan Türkiye - Sovyet Rusya Dostluk ve Kardeşlik Antlaşması ile ise, taraflar, Türkiye'nin ü̧̧ Sovyet cumhuriyeti ile, yani Gürcistan, Ermenistan ve Azerbaycan ile olan sınırların, belirlemişlerdir. Bu antlaşmanın 3. maddesi ile, ayrıca, Nahcivan'ın (koruyuculuk hakkını üçüncü bir devlete hiçbir zaman bırakmamak koşulu ile, Azerbaycan'ın koruyuculuğunda bir özerk bölge oluş̧urması da kabul edilmiştir. 13 Ekim 1921 'de Kars'ta imzalanan) Türkiye ile Ermenistan, Azcrbaycan ve.Gürcistan Arasında Dostluk Andlaşması da bir yandan bu ựç Sovyeı Cumhuriyetiyle Türkiye arasındaki sınırlan ve ilişkileri düzenlerken, aynı zamanda da 5. maddesiyle Moskova Antlaşması'nın Nahcivan'la ilgili hükümlerini tekrarlamaktayd. ${ }^{3}$

Karabağ, 7 Haziran 1923 tarihinden başlayarak, Azcrbaycan sınurlan içinde bir ozerk il olarak tanımlandı.

\section{YAKIN GEÇMIŞ ${ }^{4}$}

Karabă̆ bunalımının son dönemi 1987 - 1988'de başladı. Ermeniler, Sovyetler Birliği'nin içine düştügü durumdan ve Soguk Savaş koşullarının ortadan kalkmağa yüz tutmasından cesarct alarak, önce 1987'de Karabag ile ilgili isteklerini gündeme getirdiler, ardından da 1988'de Karabağ'da gösteriler yapmağa ve Dağlık Karabağ'da bir Ermeni Azeri çatışmasını tahrik etmeğe başladılar. Bu olaylar sırasında Ermenistan'da yaşayan Azeriler de katledilip, gö̌çe zorlandı.

1989 yılı başında Azerbaycan Hükümeti Karabağ'ın özerk statüsünü kaldırdığını açıkladı. 1 Aralık 1989'da ise Ermenistan Karabag''ı ilhak etme karannı ilan etti. 1992 başında da Azerbaycan Cumhurbaşkanı Muttaliḅov, bu bölgeyi doğrudan doğruya Cumhurbaşkanlığına bağladığını açıkladı. Bunun ardından yeni bir Ermeni hareketi Karabag'ı sard.. Ermeni milisler 26 Şubat 1992 tarihinden başlayarak saldınya ve bir soykırım boyutlarını alan katliama yeniden başladılar. Ilkbaharda Dałlık Karabą̆ bütünüyle Ermenilerin eline geçtigi gibi, Ermenistan ayrıca Karabał̆ ile Ermenistan arasında uzanan Azeri topraklarını da denetlemeye başladı. Artık fiilen, Ermenistan, Karabağ ile toprak bağlanusını kurabilmişti. Bu gelişmelerin ardından Ermenistan'ın Nahçivan'a da saidırdığı ve Türkiye'nin bu bölgeyle bağlantısını kopartmak için bir deneme yaptığı görüldü. Ancak, belki de bu Ermeni hamlesi, özellikle Karabağ'da ve Karabał ile Ermenistan arasındaki Azeri topraklarındaki işgalini saglamlaştırmak, bir pazarlık kozu cldc etmek için atılmış bir adımdı.

31smail Soysal, Tarihçeleri ve Açlklamaları ile birlikte Türkiye'nin Siyasal Andlasmaları, I.Cili (1920 - 1945), Ankara, TTK Basımevi, 1989, s. 19 - 47.

${ }^{4}$ Bu konuda özellikle bkz. : Serhat Aksen, 'Karabağ Sorunu', Uluslararası lliskilerde Olaylar ve Yorumlar, 3 (Mart 1992), s. 21 - 24. 
Karabał̆ Azerbaycan sınırlanı içinde yer alan bir bölge olduğuna göre, öncelikle Azerbaycan Hükümeti'nin turada düzeni sağlaması gerekirdi. Oysa, kendisine ait bir ordusu bulunmayan, kendi içinde bölünmüşlük yaşayan, devlet deneyimi kıt olan Azerbaycan, Karabag'da acze düşmüştür. Azerbaycan'da, eski komünist kadroların bir bölümü Muttalibov'un istifasına kadar iktidardaydı. Oysa, bu kadrolar, öteki eski komünist partisi üyeleriyle bilk: anlaşmazlık içindeydiler. Ötc yandan, eski partili kadroların hepsini karşısına alan bir Halk Cephesi grubunun politikalarının da istikrara ve işbirliğine katkıda bulunduklarını söylemek zordur. Bu karşıtlık ve iktidar mücadeleleri, eǧer đemokratik bir yapıda ve oturmuş bir devlet düzeni içinde yer alsaydı, herhalde Azerbaycan'da böylesine bir siyasal kargaşa yaşanmazd.

\section{SONUÇ :}

Bugün Ermenistan'ın niyeti, Karabağ'da 'bağımsız' bir Ermeni devletinin kuruluşunu sağlayacak koşullan yaratarak, daha sonra buradaki Ermeni çoğunluğun isteği doğrultusunda bölgeyi kendisine bağlamanın yollarını açmakur. Herhalde Ermeniler, Dağlık Karabağda bu yüzden bağımsızlık ilan etmiştir. Ermenistan Cumhurbaşkanı Levon Ter Petrosyan da herhalde böyle bir amaç için Dağlık Karabağ'da Ermenilerin self - determination haklanını kullardıklanıı soylemekıedir. 5

Ermenistan ve Azerbaycan, Bağımsız Devletler Topluluğu çerçevesinde, başıa 21 Aralık 1991 Alma Ata Antlaşmasi ve 14 Şubat 1992 Minsk Bildirisi olmak üzere, 'aralanndaki anlaşmazlıkları barış̧̧ı yollarla çözmek' konusunda belgeler imzalamışlardır. B.D.T. ne kadar gevşek bir y:apı olursa olsun, bu yapı içinde yer alan öteki devletlerin de bu anlaşmazlığın giderilmesi için çaba göstermeleri gerekir. Ancak, şimdiye dek, öteki Türk cumhuriyetleri de dahil, B.D.T. üyelerinin bu doğrultuda ciddi bir çabası görülmemiştir.

Belki de soruna kalıcı bir çözüm, daha önce Türkiye'de de önerildiği gibi, bölgede Ermenistan ile Azerbaycan arasında toprak ve nüfus deł̧işimi ile sağlanabilirdi. Ermenistan Karabag'a hakim oldıkça böyle bir çözüme yanaşması uzak bir olasılıkır ama, yine de bu çözüm formülünden kısaca söz cdilmesi gerekir. Buna göre : Azcrbaycan, Karabag'ın bir kısmını elinde tıtmakla birlikte, gerisi Ermenistan'a bırakılacaktır. Ermenistan'a ayrıca Karabaig ilis Ermenistan arasındaki koridor da bırakılacaktır. Azerbaycan ise, bunụn karşılığındi Zengezur'u (yanı Azcrbaycan ile Nahçivan'ı ayıran ve şimdi Ermenistan'ın elinde tulunan toprağı) alacaktır. Toprak deģişimiyle birlikte bu bölgelerde nüfus değişimi de ġerçekleştirilerek, Ermeni bölgesinde Azcri, Azcri bölgesinde de Ermeni bırakılnıayacakur.

Türkiye, Karabağ'daki Eirmeni saldırılanı karşısında, başıa AGIK olmak üzere, uluslararası düzeyde yogun diplonnatik çaba harcamışur. Bu'çabalar sonunda Türkiye, uluslararası alanda, Karabaģ'daki Ermeni oldu - bittisinin kabul görmemesini ve Karabağ'ın Azerbaycan toprağı olarak yeniden tanımlanmasını sağlayabilmiştir. Ancak, Ermenilerin boblgedeki yayılmacı saldırganlığı, hem de yalnızca Karabağ'ı deģil, başka yerleri de hedef alacak şekilde, büyümek egilimindedir.

${ }^{5}$ Cumburiyet 4 Haziran $199 ?$. 
Ermenistan, hukuken, Türkiye ile olan sınırlarını 1921 Kars antlaşmasıyla kabul etmiş görünmektedir. Ancak, bir yandan Ermenistan'ın bölgede giriştiği saldırganlık, ote yandan da Ermeni yetkililerinin bir türlü Tükiye'den toprak istekleri olmadığına ilişkin bir resmi açıklama yapmamakta direnmeleri, Ermenistan'ın Türk topraklanyla ilgili niyetleri konusunda güven vermemektedir. Böyle bir güven ortamını oluşturmadan Türkiye'nin Ermenistan'la ilişkilerini gcliştirmesini beklemek doğru olmayacakur. 